Case Reports

\title{
Poisoning with Amitraz, a veterinary drug, in an adolescent boy
}

\author{
N T Rajesh ${ }^{1}$, N Saravana Pandian², John Mathai ${ }^{3}$ \\ Sri Lanka Journal of Child Health, 2014; 43(1): 55-56
}

(Key words: Amitraz poisoning; child; veterinary drug)

\begin{abstract}
Introduction
Amitraz is a veterinary product belonging to formamidine group. Commercial preparations contain $12.5 \%$ to $20 \%$ of amitraz in organic solvents like xylene which add to the toxic effects. It is widely used in the treatment of generalized demodicosis in dogs and for control of ticks and mites on cattle ${ }^{1}$. There has been a recent surge in the number of reported cases in children, probably because of easy availability without prescription ${ }^{2}$. We report an adolescent boy who attempted deliberate self-harm with amitraz, and recovered without any residual damage.
\end{abstract}

\section{Case report}

A 14-year-old boy consumed approximately $0.5 \mathrm{ml}$ of amitraz following a disagreement with his father over studies. The drug had been procured for use in their pet dog, which frequently got infested with mites. $\mathrm{He}$ reported the matter to his mother about 20 minutes after consumption. The parents immediately induced vomiting with tap water and common salt and brought him to the casualty. At the time of admission the child was obtunded, with a Glasgow Coma Scale of $7 / 15$ (E2M4V1). The heart rate was $62 / \mathrm{min}$, respiratory rate was $14 / \mathrm{min}$ and the BP was $100 / 60 \mathrm{~mm} \mathrm{Hg}$. There was no abnormal odour and no increase in oral or nasal secretions. The child had bilateral constricted pupils, was hypotonic, deep tendon reflexes were depressed and plantar response was mute. Oral airway was introduced with which the oxygen saturation in room air improved. He was shifted to the Paediatric Intensive Care Unit and the electrocardiogram showed sinus bradycardia. A fluid

\footnotetext{
${ }^{1}$ Assistant Professor of Pediatrics, ${ }^{2}$ Department of Pediatrics, ${ }^{3}$ Professor of pediatrics, PSG Institute of Medical Sciences and Research, affiliated to Tamil Nadu, Dr. M.G.R. Medical University, Chennai, Tamil Nadu, India
}

(Received on 01 March 2013: Accepted after revision on 19 April 2013) bolus was given and dopamine infusion was started. Heart rate and the blood pressure normalized in 2 hours at a dopamine infusion rate of $10 \mathrm{mcg} / \mathrm{kg} / \mathrm{min}$. Infusion was weaned off and stopped at 48 hours. His vital parameters were monitored continuously. By 15 hours, he showed gradual improvement in the consciousness level. Plasma glucose (random), renal function tests and liver function tests were within normal limits. In view of the miosis, possibility of organophosphate ingestion was considered but the serum cholinesterase level was normal. Computed Tomography of brain was normal. Sensorium returned to normal by 34 hours and he was able to walk by fourth day. He was discharged on sixth day after psychiatric evaluation and parental counselling.

\section{Discussion}

Amitraz is used for controlling ectoparasitic infestation in dogs and cattle ${ }^{3}$. Accidental poisoning can occur through ingestion, inhalation or direct skin contact $^{4}$. Clinical features include hypotension, bradycardia, miosis, sedation and coma. It is due to central pre-synaptic alpha2 adrenoceptor stimulating property of the drug and is dose-dependent ${ }^{5}$.

As there is no specific antidote, patients should be managed with intensive supportive care. Since the poison is usually dissolved in organic solvents, routine gastric lavage is not recommended unless large amounts of the drug have been ingested, in which case the airway should be secured before the procedure $^{6}$. Our patient developed alteration in sensorium within 30 minutes of intake of the drug. Earlier cases reported change in sensorium in 30-120 minutes. ${ }^{4,7}$. It is likely that progression to coma did not occur in our case since the volume consumed might be low and the parents induced vomiting soon. Mild respiratory depression with hypoxia can be managed with supplemental oxygen using nasal prongs. In rare instances where respiratory depression progresses, short-term ventilatory support is mandatory till neurological recovery occurs. Hypotension and bradycardia may be refractory to 
fluid boluses, as in our case and may require vasopressors like dopamine. For isolated bradycardia without hypotension, atropine has been used in animal models to accelerate the heart rate ${ }^{8}$. Some patients may develop hyperglycemia due to alpha2 adrenergic stimulation and the resultant decrease in insulin secretion, but this was not seen in our patient ${ }^{9}$. Our patient gradually regained consciousness and had normal vital parameters 24 hours after admission. This is comparable to the previously documented resolution time of less than 48 hours $^{10}$.

With the increasing trend of keeping pets inside the house and easy availability of Amitraz, it is likely that poisoning with this drug may increase in the future. If the quantity consumed is not large and intensive supportive care is instituted early, the prognosis is good and recovery is complete. This case underlines the need for regulating sales of veterinary drugs which are toxic to humans.

\section{References}

1. Agin HA, Sebnem O, Calkavur O, Uzun H, Bak M. Amitraz poisoning: Clinical and laboratory findings. Indian Pediatrics 2004; 41: 482-6.

2. Yaramis A, Soker M, Bilici M. Amitraz poisoning in children. Human and Experimental Toxicology 2000; 19: 431-2. http://dx.doi.org/10.1191/096032700682694215

3. Queiroz-Neto A, Zamur G, Goncalves SC, Carregaro AB, Mataqueiro MI, Harkins JD. Characterization of the antinociceptive and sedative effect of amitraz in horses. Journal of Veterinary Pharmacology and Therapeutics 1998; 21: 400-5.

http://dx.doi.org/10.1046/j.13652885.1998.0015

$0 . x$

4. Jorens PG, Zandijk E, Belmans L, Schepens PJ, Bossaert LL. An unusual poisoning with the unusual pesticide amitraz. Human and Experimental Toxicology. 1997; 16: 600-1. http://dx.doi.org/10.1177/096032719701601008

5. Costa LG, Olibet G, Murphy SD. Alpha 2 adrenoceptors as a target for formamidine pesticides: in vitro and in vivo studies in mice. Toxicology and Applied Pharmacology 1984; 3: 319-28.

6. Yilmaz HL, Yildizdas DR. Amitraz poisoning, an emerging problem: epidemiology, clinical features, management, and preventive strategies Archives of Disease in Childhood 2003; 88: 1304. http://dx.doi.org/10.1136/adc.88.2.130

7. Aydin K, Per H, Kurtoglu S, et al. Amitraz poisoning in children. European Journal of Pediatrics 2002; 161: 349-50. http://dx.doi.org/10.1007/s00431-002-0945-5

8. Hsu WH, Lu ZX, Hembrough FB. Effect of amitraz on heart rate and aortic blood pressure in conscious dogs: influence of atropine, prazosin, tolazoline, and yohimbine. Toxicology and Applied Pharmacology 1986; 84: 418-22. http://dx.doi.org/10.1016/0041-008X(86)90150$\mathrm{X}$

9. Smith BE, Hsu WH, Yang PC. Amitraz-induced glucose intolerance in rats: antagonism by yohimbine but not by prazosin. Archives of Toxicology 1990; 64: 680-3. http://dx.doi.org/10.1007/BF01974698

10. Ertekin V, Alp H, Selimoglu MA, et al. Amitraz poisoning in children: retrospective analysis of 21 cases. Journal of International Medical Research 2002; 30: 203-5. http://dx.doi.org/10.1177/147323000203000215 